\title{
Cousin marriage and premarital carrier matching in a Bedouin community in Israel: attitudes, service development and educational intervention
}

\author{
Aviad E Raz, BSc, PhD, Senior Lecturer; Marcela Atar, BA, Doctoral Candidate, Department of Behavioral Sciences, \\ Ben-Gurion University of the Negev, Beer-Sheva, Israel
}

Correspondence: Dr Aviad E Raz, Department of Behavioral Sciences, Ben-Gurion University of the Negev, Beer-Sheva, Israel 84105. E-mail: aviadraz@bgumail.bgu.ac.il

(Accepted 2 September 2003)

Journal of Family Planning and Reproductive Health Care 2004; 30(1): 49-51

\begin{abstract}
Context. Premarital carrier matching is a form of genetic counselling in which two individuals are told, if both are carriers, that they have a $25 \%$ risk at each pregnancy of having a child affected by the disease for which they were tested. If only one individual is a carrier this information is not disclosed. This scheme is offered to a consanguineous Bedouin community characterised by high prevalence of genetic diseases and a religious ban on abortion.

Objective. To elicit attitudes of community members concerning cousin marriage and genetic counselling. Method. Semi-structured interviews were conducted with Bedouin respondents $(n=49)$.

Results and conclusions. Interviews revealed that a majority of Bedouin respondents confirmed the traditional and social role of cousin marriage. The main reasons given in this context were clan solidarity, interpersonal compatibility, preservation of family property, parental authority and social protection for women. A majority of the respondents also associated cousin marriage with genetic diseases. Regarding genetic testing, the majority of respondents preferred the option of premarital carrier matching, which was supposed to reduce stigmatisation, especially of women. Prenatal genetic testing was rejected on religious grounds. The result of this community-based and culture-sensitive process was a focus on premarital carrier matching.
\end{abstract}

\section{Key message points}

- In premarital carrier matching, potential partners waive their right to receive personal information, and are told instead whether they are genetically 'compatible' or not ('incompatibility' meaning that the two partners are carriers, and thus have a $25 \%$ risk at each pregnancy of having an affected child).

- Such 'couple testing' is carried out before two people are introduced, in line with the tradition of matchmaking.

- The option of premarital carrier matching is supported by health professionals and community members as culturally appropriate for traditional communities such as the Bedouins, where consanguinity increases the prevalence of genetic diseases.

- Individual testing carries a risk of stigmatisation, especially for women.

- The traditional and social roles of cousin marriage, involving clan solidarity, interpersonal compatibility, preservation of family property, social protection for women and parental authority, preserve its practice despite growing awareness among community members of the association between cousin marriage and genetic diseases.

- Further research is needed to explore the actual uptake of the genetic counselling service and its use in the decision-making process as regards marriage, family planning and reproduction.

\section{Introduction}

The Negev area in the south of Israel, which constitutes about $60 \%$ of Israel, comprises around 510000 inhabitants, of which about $23 \%$ are Bedouin and the rest are Jews. This area is less developed, economically and culturally, than the urban centre surrounding the cities of Tel-Aviv, Haifa and Jerusalem. Bedouin Arabs have been in the Negev since the 6th century, having migrated from the Arabian peninsula. Formerly a seminomadic people living from herding and agriculture, the Bedouin have been undergoing, since the 1950s and increasingly after 1967 , a rapid process of sedenterisation. In 1998 about $50 \%$ of the Bedouin population lived in seven towns which were planned for them by Israeli governments, while the rest lived in scattered encampments.

The Bedouin population of the Negev is characterised by low socio-economic and educational levels, high levels of unemployment, high fertility rates (about 8.0 children per woman, on average, as opposed to 3.9 children per women on average in the Negev district), poor utilisation of prenatal services, and a Muslim ban on pregnancy termination. 1,2 Consanguineous marriages, particularly cousin marriage, are highly prevalent and polygyny is common. To assess the prevalence of consanguinity (for which there are no official records) we interviewed the local marriage registrar in a Bedouin community targeted for genetic research and counselling. The number of new marriages in this community (population size approximately 3000) was 57 during the period 1999-2002. A total of $51(89 \%)$ of these marriages were consanguineous, with $21(37 \%)$ being double firstcousin marriages, $12(21 \%)$ first-cousin marriages, seven $(12 \%)$ uncle-niece marriages, five $(9 \%)$ marriages of first cousins once-removed, and six (11\%) secondcousin marriages. Approximately similar frequencies of double first-cousin marriage, which is the preferred pattern of endogamy among the Bedouins, were found in other studies conducted in the larger Bedouin population. ${ }^{1}$ In the last decade, infant mortality attributable to genetic conditions was approximately four times higher in the Bedouin population as compared to the Jewish population in the Negev area. At the same time, less than $10 \%$ of eligible Bedouin women underwent amniocentesis, compared to about $50 \%$ of Jewish women in the area. ${ }^{3}$ One of the obvious reasons for not being tested is the Muslim objection to abortion.

As a result of genetic studies that began around 1991, more than 10 genetic diseases have been mapped in the Negev Bedouin population, including thalassemia and congenital hearing loss (prevalence of affected individuals estimated at $4 \%$ and $3 \%$, respectively), ${ }^{4}$ which are the genes currently included in the genetic screening service offered to a Bedouin community targeted for the piloting of premarital carrier matching. 


\section{Method}

Semi-structured interviews, conducted in Hebrew and Arabic, were held during the period January 2001-November 2002 with Bedouin men $(\mathrm{n}=26)$ and women $(\mathrm{n}=23)$ stratified by age (range, 16-30 years), consanguinity level, susceptibility (measured by the existence of a family relative affected by a genetic disease) and education. Questionnaire surveys were found to be an impractical option in the Bedouin population owing to difficulties of access, literacy and compliance. Difficulties of access and compliance were also responsible for the fact that to date only 49 Bedouin men and women have been interviewed. Interviews lasted between 1 and 2 hours and were usually conducted at the respondent's home. Questions used in the interviews included perceptions of genetic testing and of cousin marriage, specifically in terms of genetic risk, social goals, paternal authority and romantic love. The interviewers asked these questions in the same way but in an open-ended manner (without offering specific options for responses, so as to let respondents speak their minds in their own words). While the interview was structured around these standard questions, open discussions also developed around particular questions. A brief summary of the research was presented to each interviewee prior to the interview. All participants had the right to refrain from answering any question and could also withdraw from the interview at any time. The transcribed interviews were analysed to reach agreement between the researchers on the categorisation of attitudes related to each question. Disagreements were resolved by discussion.

\section{Results}

Attitudes regarding cousin marriage that were categorised from the interviews are detailed in Table 1. Due to space limitations the results of the analysis of attitudes regarding cousin marriage are presented in a succinct form, based on the categorisation of attitudes as representing agreement/disagreement with the questions posed.

Regarding genetic testing, the majority $(44 ; 90 \%)$ of respondents preferred the option of premarital carrier matching over individual testing, because the former was supposed to reduce stigmatisation, especially in the case of women. Prenatal genetic testing was rejected on religious grounds. Many of the respondents commented that if a woman were found to be a carrier then this would make it difficult for her to get married. Furthermore, respondents commented that individual testing would not keep the carrier status confidential, since 'information like this travels fast in our community'. Many of the male respondents said that in case of individual testing they

Table 1 Attitudes regarding cousin marriage among Bedouin respondents

\begin{tabular}{llll}
\hline Attitude & $\begin{array}{l}\text { Total }(\%) \\
(\mathrm{n}=49)\end{array}$ & $\begin{array}{l}\text { Males }(\%) \\
(\mathrm{n}=26)\end{array}$ & $\begin{array}{l}\text { Females }(\%) \\
(\mathrm{n}=23)\end{array}$ \\
\hline $\begin{array}{l}\text { Cousin marriage is associated } \\
\text { with increased risk for affected } \\
\text { babies }\end{array}$ & $32(65)$ & $18(69)$ & $14(61)$ \\
$\begin{array}{l}\text { Cousin marriage serves social } \\
\text { goals }\end{array}$ & $18(37)$ & $6(23)$ & $12(52)$ \\
$\begin{array}{l}\text { Cousin marriage is inevitable } \\
\text { because parents do not allow } \\
\text { out-marriage }\end{array}$ & $11(22)$ & $3(11)$ & $8(35)$ \\
$\begin{array}{l}\text { Cousin marriage is good if it } \\
\text { has a romantic basis } \\
\text { ('love marriage') }\end{array}$ & $11(22)$ & $6(23)$ & $5(22)$ \\
$\begin{array}{l}\text { Cousin marriage reflects too } \\
\text { much parental intervention }\end{array}$ & $4(8)$ & $4(15)$ & $0(0)$ \\
\hline
\end{tabular}

would insist on asking the girl's father whether she was a carrier before considering the option of marriage. Hence, individual carrier status (particularly of women) would become part of the premarital negotiation phase.

\section{Discussion}

A majority of Bedouin respondents $(29 ; 59 \%)$ confirmed the traditional and social role of cousin marriage. The main reasons given in this context were clan solidarity, interpersonal compatibility, preservation of family property, social protection for women and parental authority. There were a lot more women who supported this traditional view. Some women spoke about cousin marriage as a 'safety net' for the bride who leaves her father's home. Interestingly, the fact that $32(65 \%)$ of the respondents associated cousin marriage with genetic diseases was in contrast to the fact that the majority of the Bedouins supported and practised cousin marriage. The minority attitude regarding romantic love was ambiguous, since it was perceived to be in opposition to tradition. The generalisability of the findings should, however, be considered in light of the small sample size and the methods by which the respondents were surveyed. The respondents in this study may not mirror the views of the whole Bedouin community. However, the results from the 49 respondents are interesting in themselves.

Providing multicultural and community-based services is a major challenge to the profession of genetic counselling. Taking into account community norms such as the importance of cousin marriage, matchmaking and the religious ban on abortion, genetic counselling to the Bedouin was planned by counsellors to focus on premarital carrier matching. In this system, potential partners waive their right to receive personal information, and are told instead whether they are genetically 'compatible' or not ('incompatibility' meaning that the two partners are carriers, and thus have a $25 \%$ risk at each pregnancy of having an affected child). If neither or just one of the two partners is a carrier, they are told that they are genetically 'compatible'. Such 'couple testing' is carried out before two people are introduced, in line with the tradition of matchmaking. Since there could be as yet unidentified mutations within the population, it is not possible to state with confidence that any cousin marriage that is compatible is also 'safe'. The counsellors thus explain that compatibility (or incompatibility) was tested only with regard to specific mutations. Rather than preaching against consanguinity, premarital carrier matching was offered by counsellors so as to promote what they termed 'healthy consanguinity'.

The carrier matching scheme was modelled after Dor Yeshorim (literally 'upright generation' in Hebrew), a genetic screening programme developed more than a decade ago by the global orthodox Ashkenazi-Jewish community. ${ }^{5}$ In Dor Yeshorim, individual results are stored in a secure database so that individuals need only be tested once, but matchmakers can check before introducing two individuals whose results are recorded in the database. The genetic counsellors plan to build up a similar secure database in which Bedouin test results can be confidentially stored. Unlike the Orthodox Jewish community, the Bedouins do not have a strong central leadership, religious or otherwise, and their uptake of medical services is much lower. These differences highlight the significance of cross-cultural education in the case of the Bedouin. Following an Institutional Review Board ethical approval, 25 at-home educational sessions have so far been conducted by specially-trained Bedouin instructors with at-risk Bedouin families, and the vast majority $(95 \%)$ of families have expressed a preference for premarital carrier matching. 


\section{Conclusions}

The focus on premarital carrier matching was presented in this study as the result of a community-based and culturesensitive process. Embedding genetic counselling in the Bedouin community was done for the purpose of marriage and family planning, and is expected to lead eventually to a reduction in the prevalence of affected babies. It remains to be seen whether, in the Bedouin setting, an incompatible result derived from premarital carrier matching would indeed be acted upon. Further research is needed to explore the actual uptake of the genetic counselling service and its use in the decision-making process as regards marriage, family planning and reproduction.

\section{Acknowledgements}

The authors wish to thank all the Bedouin respondents and genetic counsellors who participated in this study. They are also indebted to the anonymous journal reviewers for their useful comments. The authors would like to acknowledge the co-operation of two co-investigators who initiated and oversaw the project described here and who were responsible for the tremendous genetic and epidemiological work that preceded this project, namely Profs Ilana Shoham-Vardi and Rivka Carmi.
Statements on funding and competing interests

Funding. This study was funded by grants from the Israel Foundation Trustees (Project PS14/3) and the Israel Science Foundation (Grant 769/00-2).

Competing interests. None identified.

References

1 Weitzman D, Shoham-Vardi I, Elbedour K, et al. Factors affecting utilization of prenatal testing for fetal abnormalities in a traditional society. Community Genet 2000; 3: 45-92.

2 Lewando-Hundt G, Shoham-Vardi I, Beckerelg I, et al. Knowledge, action and resistance: the selective use of prenatal screening among Bedouin women of the Negev, Israel. Soc Sci Med 2001; 52: 561-569.

3 Davidov B, Goldman B, Akstein E, et al. Prenatal testing for Down syndrome in the Jewish and non-Jewish populations in Israel. Isr $J$ Med Sci 1994; 30: 629-633.

4 Carmi R, Elbedour K, Weitzman D, et al. Lowering the burden of hereditary diseases in a traditional inbred community: ethical aspects of genetic research and its application. Sci Context 1998; 11(3-4): 391-395.

5 Ekstein J, Katzenstein H. The Dor Yeshorim story: community-based carrier screening for Tay-Sachs disease. Adv Genet 2001; 44: $297-310$

\title{
SERVICE DELIVERY
}

\section{Decision making and referral prior to abortion: a qualitative study of women's experiences}

\author{
Usha Kumar, MRCOG, DFFP, Specialist Registrar; Paula Baraitser, MB BS, MFFP, SCMO; Sheila Morton, RGN, RM, Women's \\ Health Researcher; Helen Massil, MRCOG, MFFP, Consultant, Department of Sexual and Reproductive Health, Southwark \\ Primary Care Trust, London, UK
}

Correspondence: Dr Usha Kumar, Department of Sexual and Reproductive Health, Southwark Primary Care Trust, St Giles Hospital, St Giles Road, London SE5 7RN, UK. E-mail: akumar5902@aol.com

(Accepted 21 October 2003)

Journal of Family Planning and Reproductive Health Care 2004; 30(1): 51-54

\begin{abstract}
Background. Despite abortion being one of the most common gynaecological procedures performed in the UK, significant regional variation exists in access to services. Objective. This study explores women's experience of referral for abortion in three inner London boroughs to determine if services met their expectations.

Method. In-depth interviews conducted with 21 women of varying ages, gestations and ethnicity, 3-9 weeks after termination of their pregnancy. The data were subjected to qualitative analysis.

Results. Most women had made a decision to proceed with abortion before approaching the health service, and expected non-judgemental support, information and prompt referral. We found variations in the extent to which these expectations were met. Delays in referral occurred when health professionals either required women to have more thinking time, referred them elsewhere for pregnancy testing or avoided discussing abortion. This was further compounded by difficulties in making appointments via the centralised telephone booking service. The brief counselling session offered to most women by the abortion providers, although helpful to some women, was viewed as unnecessary and intrusive by others.

Conclusions. Most women seeking an abortion prefer not to discuss their decision but expect information and prompt referral. Delays in referral cause distress and later abortions and should be avoided. High-quality counselling should be targeted at those in need.
\end{abstract}

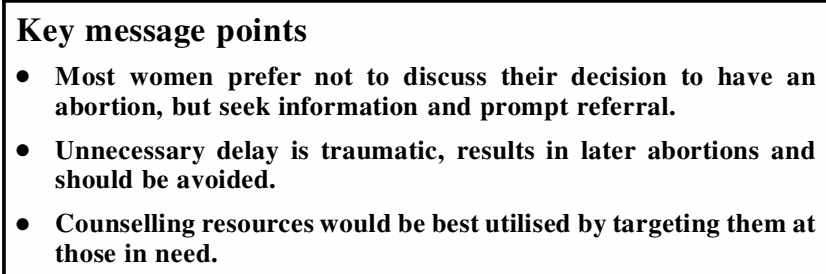

\section{Introduction}

Induced abortion is one of the most common gynaecological operations performed in Great Britain with one in three women undergoing an abortion by the age of 45 years. ${ }^{1,2}$ The Royal College of Obstetricians and Gynaecologists (RCOG) guidelines on 'The Care of Women Requesting Abortion' sets quality standards for abortion services but there remains significant regional variation in access to and quality of services provided. 1,3,4

The National Health Service (NHS) Plan requires each NHS Trust in England to obtain feedback from patients about their experiences of care ${ }^{5}$ but there has been little work to date on women's experience of abortion services. Questionnaire surveys provide some information ${ }^{6-9}$ but cannot provide a detailed account of women's experience of this procedure, and in-depth qualitative data are scarce. ${ }^{10-12}$ Data on the experience of women using the NHS abortion service in three inner London boroughs are presented, from the time the women suspected that they were pregnant until their first visit for assessment prior to the abortion procedure. 